\title{
Sn-Ag-Cu Nanosolders: Solder Joints Integrity and Strength
}

\author{
ALI ROSHANGHIAS, ${ }^{1,4}$ GOLTA KHATIBI, ${ }^{2}$ ANDRIY YAKYMOVYCH, ${ }^{1}$ \\ JOHANNES BERNARDI, ${ }^{3}$ and HERBERT IPSER ${ }^{1,5}$ \\ 1.-Department of Inorganic Chemistry (Materials Chemistry), University of Vienna, 1090 \\ Vienna, Austria. 2.-Faculty of Technical Chemistry, Vienna University of Technology, 1060 \\ Vienna, Austria. 3.-USTEM, Vienna University of Technology, 1060 Vienna, Austria. 4.-e-mail: \\ Ali.roshanghias@univie.ac.at.5.—e-mail: Herbert.ipser@univie.ac.at
}

\begin{abstract}
Although considerable research has been dedicated to the synthesis and characterization of lead-free nanoparticle solder alloys, only very little has been reported on the reliability of the respective joints. In fact, the merit of nanoparticle solders with depressed melting temperatures close to the $\mathrm{Sn}-\mathrm{Pb}$ eutectic temperature has always been challenged when compared with conventional solder joints, especially in terms of inferior solderability due to the oxide shell commonly present on the nanoparticles, as well as due to compatibility problems with common fluxing agents. Correspondingly, in the current study, Sn-Ag-Cu (SAC) nanoparticle alloys were combined with a proper fluxing vehicle to produce prototype nanosolder pastes. The reliability of the solder joints was successively investigated by means of electron microscopy and mechanical tests. As a result, the optimized condition for employing nanoparticles as a competent nanopaste and a novel procedure for surface treatment of the SAC nanoparticles to diminish the oxide shell prior to soldering are being proposed.
\end{abstract}

Key words: Nanosolders, nanojoints, Pb-free solders, nanoparticles, SAC

\section{INTRODUCTION}

In the long run, the traditional lead-tin ( $\mathrm{Pb}-\mathrm{Sn})$ solders have gradually been substituted with environmentally friendly $\mathrm{Pb}$-free solders, which are currently employed by far in most of the electronic packaging industries. Nonetheless, the superior properties of the $\mathrm{Pb}-62 \mathrm{Sn}$ (wt.\%) solders are still emphasized as a benchmark for the variety of $\mathrm{Pb}$ free solders. Most of the components assembled to the printed circuit boards (PCBs) in the soldering process are designed primarily for $\mathrm{Sn}-\mathrm{Pb}$ soldering with a thermal tolerance up to a maximum temperature of $240^{\circ} \mathrm{C}$. On the contrary, the higher melting temperatures of the typical $\mathrm{Pb}$-free solders such as $\mathrm{Sn}-\mathrm{Ag}$ (SA) and $\mathrm{Sn}-\mathrm{Ag}-\mathrm{Cu}$ (SAC) require reflow temperatures at or above $240^{\circ} \mathrm{C}$. That makes it more difficult to optimize the reflow process for all components on the PCB. ${ }^{1-5}$ To tackle this issue in the transition process toward $\mathrm{Pb}$-free solders, a

(Received November 12, 2015; accepted April 25, 2016;

published online May 13, 2016) great many number of studies have been targeted on the synthesis of nanoparticles of pure $\mathrm{Sn}^{6}$ as well as near-eutectic $\mathrm{SA}^{1,2}$ and SAC alloys ${ }^{1,7,8}$ as promising candidates for the next generation of $\mathrm{Pb}$ free solders due to their reduced melting temperatures.

In a previous study, ${ }^{9}$ the eutectic melting temperature of the SAC nanoparticles has been formulated as a function of the particle radius $(r)$ by a nonlinear hyperbolic regression with a deviation of $<2^{\circ} \mathrm{C}$ :

$$
T_{\text {eut }}\left( \pm 2^{\circ} \mathrm{C}\right)=\frac{218.7 r}{1.362+r}
$$

As a matter of fact, melting point depression in nanosolders was the primary goal for most of the research on nanosolders, since the melting temperature of the near-eutectic SAC bulk alloys is approximately $217^{\circ} \mathrm{C}$, about $34^{\circ} \mathrm{C}$ higher than that of the conventional Sn-Pb solders. ${ }^{10} \mathrm{As}$ an example, a melting point depression of $26.6^{\circ} \mathrm{C}$ could be achieved for the SAC nanoparticles with an average 
diameter of $18 \mathrm{~nm} .{ }^{7}$ It is worth mentioning that according to the joint standard (J-STD) 005 specification, ${ }^{11}$ the commercial solder particle powders are classified in eight sizes. The smallest solder particles in this list intended for extreme fine pitch work is still in the range of $2-8 \mu \mathrm{m}$, which is larger than the realm, where melting point depression of particles comes into play.

However, the difficulty lies in the reflowing process of these nanopowders, which can indeed cast doubts on the practical applicability of these novel solders. Reflowability of a solder paste can be defined as the ability to achieve a clean metallic surface on a substrate after reflowing so that a complete coalescence of the solder powder particles and good wetting of molten solders on the surface of the substrate can be achieved. ${ }^{12}$ It was reported in the literature that nanoparticles after melting frequently turned into micro-size powders rather than bulk spheres, which implies an impurity contribution either due to the employed surfactant, or to the extreme surface oxidation of the nanoparticles. ${ }^{2}$ It is well known that if solder powders are intensely oxidized at the production stage, so-called solder balling defects can occur. As the oxidized particles require aggressive activation to be removed and do not melt at normal reflow temperatures, such particles will not be attached to a metal surface and will be carried away with the flux, leaving satellite solder balls. ${ }^{1,13}$

Koppes et al. ${ }^{4}$ produced a nanosolder paste by combining the nanoparticles with flux and reported that although target melting temperatures were achieved, nanoparticle coalescence was limited due to the organic layer adsorbed on the metal surface during chemical synthesis, which was defined as a combination of the capping layer, excess flux and residual precursors. It was also reported that even the thin layer of tin oxide prevented the coalescence of the metallic tin. ${ }^{14}$ In our previous study, scanning electron microscopy (SEM) and transmission electron microscopy (TEM) investigations indicated that the nanoparticles consisted of a metallic Sn-rich core and an amorphous tin and oxygen rich shell. ${ }^{7}$ In another study on SAC nanoparticles ${ }^{8}$ it was observed that even during repeated differential scanning calorimetry (DSC) heating cycles, the bulk melting temperature was never reached, but the successive heating curves looked rather similar with a constantly depressed melting temperature. It can be speculated that the superficial oxide layer surrounding the individual particles prevented the metallic cores of the particles from agglomeration and further coalescence after melting, thereby the nanoparticles remained nanoparticles or microparticles even after melting. Likewise, Gao et al. reported that the oxide layer on Sn-based nanowires and nano-rods dramatically affect the melting behavior of the nanosolders. ${ }^{15}$

As a matter of fact, oxide free solder powder is hardly attainable, and although excessive oxide content is detrimental to reflowability and can cause solder balling, powder containing oxygen in the range of $50-200 \mathrm{ppm}$ is generally considered satisfactory. ${ }^{11-13}$ However, the ratio of surface area to volume of a sphere increases as the particle size reduces, and so, for a given oxide thickness, more oxide will be present in the nanosolder paste.

A few pyrometallurgical techniques are reported in the literature, mainly for the recovery of tin from oxidized tin scrap. ${ }^{16,17}$ However, these are in all cases high temperature processes, which cannot be practiced for nanosolders. For example, Kim et al. ${ }^{16}$ report that the reduction of $\mathrm{SnO}_{2}$ by hydrogen is thermodynamically favorable in the temperature range above about $550^{\circ} \mathrm{C}$ according to the reaction:

$$
\mathrm{SnO}_{2}+2 \mathrm{H}_{2}(\mathrm{~g})=\mathrm{Sn}(\mathrm{s}, \mathrm{l})+2 \mathrm{H}_{2} \mathrm{O}(\mathrm{g})
$$

The removal of tin oxide was also attempted using mechanical attrition (grinding in a ball mill) and chemical dissolution of the tin oxide layer by means of hydrochloric acid (HCl). ${ }^{14}$ The tin oxide layer of powders bigger than $53 \mu \mathrm{m}$ was reported to be almost completely removed by an acidic treatment with $\mathrm{HCl}$ at room temperature and agitation for 30 min. Employing acidic fluxes and soaking in acidic solutions have also been sought in some studies in order to remove the oxide shell of nanosolders. $1,5,10,15$

In light of the necessity to verify the reliability of the lead-free nanopowder solders, the goal of this work is to produce a prototype nano-paste by combining nanoparticle SAC solders in different size with a flux vehicle and to propose solutions for the aforementioned issues facing nanoparticle soldering.

\section{EXPERIMENTAL PROCEDURE}

The prototype nanopaste was produced by mechanically mixing of SAC nanoparticles with a compatible, mild Pb-free solder flux (rosin-based Indium no-clean Tacflux 089HF; Indium Co., Milton Keynes, U.K.) for about 15 min to promote uniform distribution. Moreover, a more aggressive, acidic flux vehicle (Chemet $\mathrm{Z}-02, \mathrm{pH} \approx 2$; Chemet, Staudt, Germany) comprising zinc chloride and ammonium chloride was also employed for comparison. It is noteworthy to mention that as the aggressive fluxes tend to leave corrosive contaminants that could adversely affect the reliability of the electronic assemblies, these fluxes are required to be carefully cleaned after reflowing. ${ }^{18}$ Industrial solder pastes contain normally 75-90 wt.\% metallic powders; however, for the nanopaste with relatively higher activity to the environment, a lower powder content range (70-80 wt.\%) has been determined to be loaded into the flux (20-30 wt.\%).

Sn-3.8Ag-0.7Cu (wt.\%) nanoparticles were synthesized with three different average particle diameters $(18 \mathrm{~nm}, 34 \mathrm{~nm}$, and $50 \mathrm{~nm})$ via a chemical 
reduction technique by employing sodium borohydride and polyvinylpyrrolidone (PVP) as the reducing and surfactant agent, respectively. The details on the synthesis procedure of the nanoparticles and their melting point depression compared to bulk are given in Refs. 7 and 9, respectively. The composition and properties of the nanopaste samples produced for this study are listed in Table I. In addition, in order to draw a fair comparison between nano and micro size solder pastes, a representative (type 6) micron-size Sn-3.8Ag-0.7Cu (wt.\%) powder (5$15 \mu \mathrm{m}$, Heraeus, Hanau, Germany) was chosen and processed with the flux in the same fashion as the nanopowder; it is denoted by "Micro-S" in Table I. It is worth noting that commercial micron-size solder powders are produced by gas atomization technique.

As to conduct a feasibility study on employing nanopastes in an actual situation, single shear-lap joints were produced by filling the overlap area between two dogbone-shaped $\mathrm{Cu}$ strips with nanopaste. Prior to soldering, the copper strips were polished with emery paper (up to 1000-grit), soaked shortly in diluted nitric acid solution, rinsed in distilled water and dried with ethanol. The geometry of the joint samples is shown schematically in Fig. 1, indicating the joint area of $3 \mathrm{~mm} \times 5 \mathrm{~mm}$. The alignment of the joint configuration was constrained by an alumina boat jig, which was designed to enclose the copper strips. The whole set-up was then subjected to the reflow soldering process in a reflow furnace (LPKF Zelflow RO4) by implementing a near-industrial reflow temperature profile for commercial solder paste and a modified one for nanopaste.

The mean reflow temperature recommended for $\mathrm{Sn}-3.8 \mathrm{Ag}-0.7 \mathrm{Cu}$ solders is $243^{\circ} \mathrm{C}\left( \pm 5^{\circ} \mathrm{C}\right)$, which is $26^{\circ} \mathrm{C}$ higher than its melting temperature, ${ }^{3,5}$ in order to secure complete melting of the solder. Likewise, the reflow temperature for nanosolders was selected $26^{\circ} \mathrm{C}$ above their melting temperature derived from DSC measurements and verified by Eq. 1 . The dwell time below the peak reflow temperature was decided to be minimized to reduce inter-diffusion of nanoparticles before melting.

The joint samples were subsequently polished on both sides, as to remove the extruded solder and flux residue from the edges. The shear strength of the solder joint was assessed, implementing a $\mu$-strain tensile machine (ME 30-1, Fuerstenfeld, Austria) with a crosshead stroke resolution of $0.04 \mu \mathrm{m}$ and a minimum load resolution of $10 \mathrm{mN}$. The tests were performed displacement controlled using a fixed crosshead speed of $0.05 \mathrm{~mm} / \mathrm{min}$ for all the samples at room temperature. Correspondingly, the mean values of the ultimate shear strength (USS) of 2-4 samples for each sample condition were calculated and reported for comparison. Scanning electron microscopy (SEM) studies were performed on a scanning electron microscope (Zeiss Supra 55 ESEM) and TEM investigations were conducted by using a (FEI TECNAI F20 TEM) microscope equipped with energy-dispersive spectroscopy (EDS) and energy-loss spectroscopy (EELS). For differential scanning calorimetry (DSC) a TG-DSC instrument (Labsys, SETARAM, Lyon) was employed, and experiments were carried out over the temperature range from room temperature to $400^{\circ} \mathrm{C}$ at a heating rate of $5 \mathrm{~K} / \mathrm{min}$ under the flow of $\mathrm{Ar}$ gas. The instrument was calibrated by comparison of the melting temperatures of metallic In, Sn and $\mathrm{Cu}$ (99.999 mass\% purity) with tabulated values with an accuracy of the melting temperature of $\pm 0.5^{\circ} \mathrm{C}$.

Table I. List of samples and their properties

\begin{tabular}{|c|c|c|c|c|c|}
\hline $\begin{array}{l}\text { Sample } \\
\text { no. }\end{array}$ & $\begin{array}{l}\text { Nanoparticle } \\
\text { size } D(\mathbf{n m})\end{array}$ & $\begin{array}{c}\text { Melting } \\
\text { temperature } T_{\mathrm{m}}\left({ }^{\circ} \mathrm{C}\right)\end{array}$ & Purification & Flux & $\begin{array}{c}\text { Shear strength } \\
\text { of solder joints } \\
\text { USS (MPa) }\end{array}$ \\
\hline $\mathrm{S} 1$ & 18 & 189 & No & Tacflux & - \\
\hline $\mathrm{S} 2$ & 18 & 189 & No & Z-02 & - \\
\hline S3 & 34 & 202 & No & Tacflux & $<6$ \\
\hline $\mathrm{S} 4$ & 34 & 202 & No & Z-02 & $10 \pm 2$ \\
\hline S5 & 50 & 207 & No & Tacflux & $15 \pm 3$ \\
\hline S6 & 50 & 207 & No & Z-02 & $20 \pm 2$ \\
\hline $\mathrm{P}-\mathrm{S} 1 * *$ & $36-39 *$ & 204 & Yes & Tacflux & $26 \pm 1$ \\
\hline P-S2 & $36-39 *$ & 204 & Yes & Z-02 & $26 \pm 2$ \\
\hline P-S3 & $58-66^{*}$ & 209 & Yes & Tacflux & $28 \pm 4$ \\
\hline P-S5 & $66-70^{*}$ & 210 & Yes & Tacflux & $31 \pm 3$ \\
\hline Micro-S & $5000-15,000$ & 217 & No & Tacflux & $33 \pm 1$ \\
\hline
\end{tabular}

*Calculated from Eq. 1. ${ }^{* *}$ The prefix (P-S $x$ ) denotes the samples ( $\mathrm{S} x$ ) after purification process. 
(a)
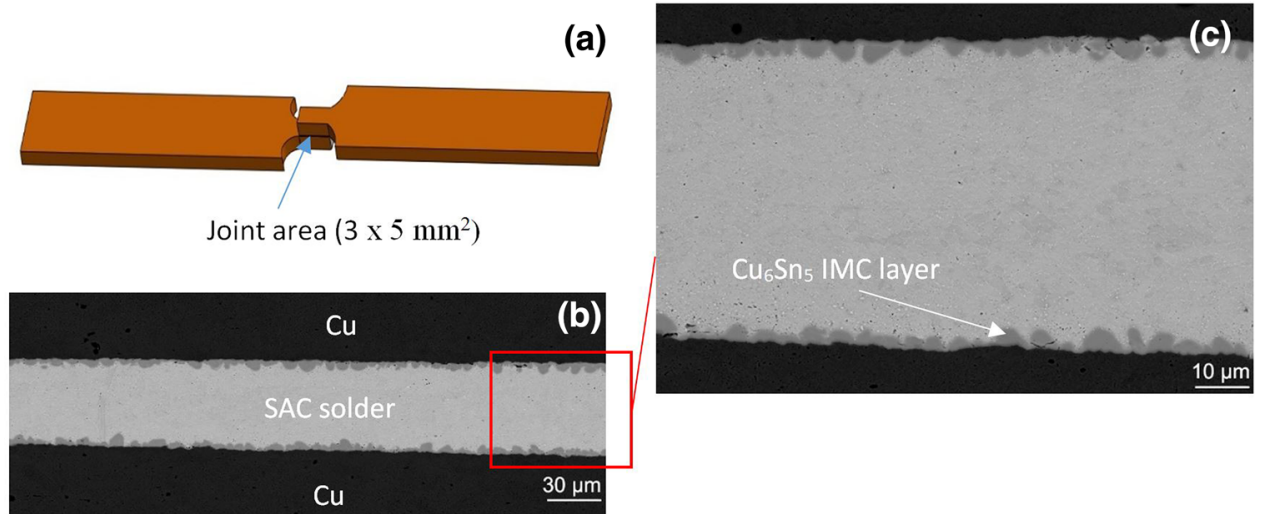

Fig. 1. Schematic configuration of the single shear lap solder joints (a) and a typical SEM cross-sectional images of the soldered area in two magnifications $(b, c)$.

\section{RESULTS AND DISCUSSION}

\section{Solder Joints from As-Synthesized Nanoparticles}

Figure $1 b$ and $c$ shows the cross-sectional images of a solder joint in two magnifications. In the course of the soldering process, metallurgical reactions between solder and copper substrate form a reaction layer of the intermetallic compound $\mathrm{Cu}_{6} \mathrm{Sn}_{5}, 19$ which is highlighted in Fig. 1. It is known that the mechanical behavior of the joint strongly depends on the characteristics of the intermetallic (IMC) reaction layer and the solder, depending on aging time and temperature, IMC thickness, gap size, etc. ${ }^{20,21}$ To refrain from any discrepancies due to the IMCs, the reflowing set-up was designed so that the fracture occurs preferentially inside the solder bulk. For instance, as to promote solder bulk fracture, the gap size was considered to be relatively broad (approximately $60 \mu \mathrm{m}$ as shown in Fig. 1b) and no further thermal aging was applied to the solder joints.

The fracture mode in the shear test of joints made from nanosolder pastes was determined by visual observation and SEM. As revealed by the shear test results in Table I and Fig. 2, the smaller the nanoparticles, the poorer the joint strength. In fact, the fracture for the samples S1 and S2 took place immediately in the early stages of shear loading. The representative fracture surface is presented in Fig. 3, showing a region where the solder powder particles failed to coalesce and remained isolated as ball-shaped defects in the middle of the joint. EDX analysis proved that these solder balls are surrounded by a tin oxide shell. Moreover, a fraction of organic impurities is also discernible in this figure. It can be speculated that a combination of the surfactant (PVP) and residual precursors possibly adsorbed on the surface of as-synthesiszed nanoparticles, ${ }^{7}$ as well as the excess flux, which was not completely driven away from the joint interface due to the deficient reflowing of nanoparticles, are the main reasons for this organic residue.

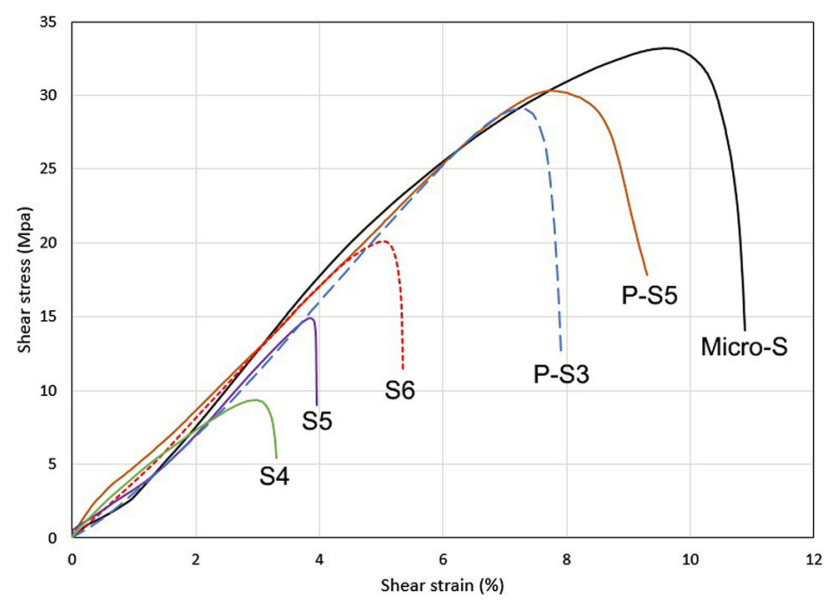

Fig. 2. Shear stress-strain curves of the solder joints.

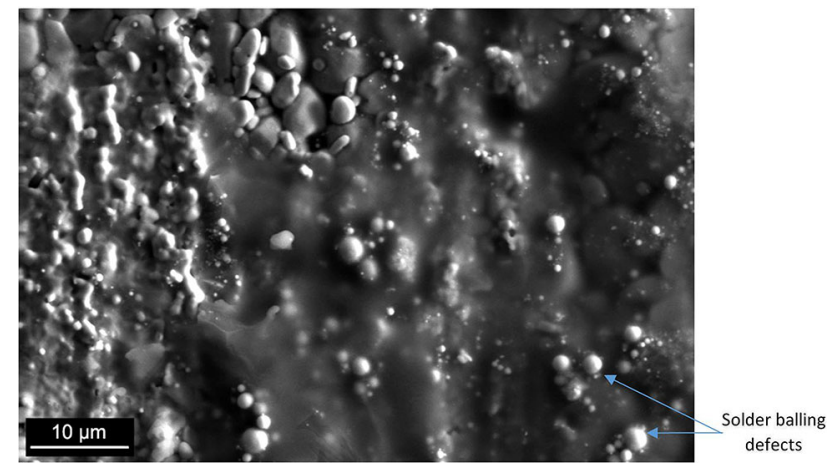

Fig. 3. The SEM fractograph of the nano-joint (S1), demonstrating the lack of coalescence of nanoparticles and solder balling effect in the joint.

Replacing the rosin-based flux with a more acidic one, in sample $\mathrm{S} 2$, did not enhance the solderability of these powders. Moreover, even increasing the reflowing peak temperature to that of the bulk solder did not significantly influence the shear strength of these joints. Apparently, removal of the oxide shell on these nanoparticles required 
special treatment before the reflow. As shown in Table I, by increasing the nanoparticle size, the shear strength of the corresponding joint significantly enhanced, implying better solderability in terms of presumably better coalescence of the bigger nanoparticles. For instance, sample $\mathrm{S} 4$ with the average particle size of $34 \mathrm{~nm}$, exhibited an ultimate shear stress (USS) of $10 \mathrm{MPa}$, whereas for sample S6 with the average particle size of $50 \mathrm{~nm}$, the USS reached to $20 \mathrm{MPa}$, a two times higher value than that of the former one. In addition, one can notice that the acidic flux (Z-02) improved the strength of the solder joints more pronounced compared to the rosin-based flux, as the particle size increases.

Nonetheless, in comparison to the micropowder sample, the nanopaste samples still exhibit remarkably inferior joint strength, which necessitates further processing for nanopowders prior to soldering.

\section{Purification Stage: Oxide Shell Dissolution}

According to the results obtained for as-synthesized nanopowders, it was deduced that the removal of the oxide shell from the nanoparticles is the key step for obtaining reliable solder joints. It can be assumed that re-oxidation can hardly occur when the deoxidized, surface-cleaned solder powder is eventually getting mixed with flux, since the flux encapsulates and isolates each particle from air exposure.

For the removal of the oxide shell of the nanoparticles, several acidic solutions were examined in this study; finally, a novel acetic acid-sodium acetate buffer solution based on $2 \mathrm{wt} \% \mathrm{HCl}$ was developed and adjusted for the dissolution of tin oxide. For comparison, an aqueous solution of $2 \mathrm{wt} . \% \mathrm{HCl}$ was also prepared and examined. As-synthesized nanopowders were brought into the solution together with a zinc rod, and the solution was stirred for $2 \mathrm{~min}$. In this reaction, a reactive form of hydrogen (nascent hydrogen) is produced in situ in the reaction mixture. Nascent hydrogen can reduce tin oxide to tin, as follows:

$$
\begin{array}{r}
\mathrm{Zn}+2 \mathrm{H}^{+} \rightarrow \mathrm{Zn}^{2+}+2[\mathrm{H}]_{(\text {Nascent Hydrogen })} \\
\mathrm{SnO}_{x}+2 x[\mathrm{H}]_{(\text {Nascent Hydrogen })} \rightarrow \mathrm{Sn}+x \mathrm{H}_{2} \mathrm{O}
\end{array}
$$

It was found that for the aqueous $\mathrm{HCl}$ solution, the reaction started to be vigorous at $\mathrm{pH}$ values below 1.9 , whereas the optimum $\mathrm{pH}$ for an $\mathrm{HCl} /$ sodium acetate buffer solution was observed around 2.6. However, in order to maintain a relatively constant $\mathrm{pH}$ value during the reaction, the buffer solution was much more effective and was, therefore, chosen as the optimum reaction condition. The processed nanoparticles were subsequently filtered and rinsed several times with a large amount of absolute ethanol. The transition in the morphology of as- synthesized nanoparticles upon purification is illustrated in Fig. 4, which will be discussed later.

\section{Solder Joints from Purified Nanoparticles}

As denoted by the prefix (P-S) for purified samples in Table I and Fig. 2, the shear strength of the solder joint dramatically increased after the purification process. It can be inferred that the mechanical strength of joints made from the nanopaste after removal of the oxide shell reached values comparable to that of the commercial micro-powder paste. The corresponding fractograph of the solder joint, as illustrated in Fig. 5, indicates a ductile fracture mode with typical shear bands. As observed, the ductile fracture appeared in the bulk of the solder joints during the shear process and the fracture surface did not show any evidence of entrapped solder balls as before. A very similar fracture surface was also observed in the joints made from the micro-powder. It must be concluded that the purification process described above resulted in quasi-oxide-free nanoparticles, which ensured the reliability of the solder joint.

\section{In Situ TEM Studies}

Prolonged TEM operation at $200 \mathrm{kV}$ was accompanied by in situ melting and coalescence of the nanoparticles, especially when high currents were used. In fact, the localized heat generated by electron beam irradiation was sufficient for the melting of SAC alloy nanopowders, which is found to be favorable and helpful in the current study in investigating the melting behavior of nanosolders. This melting phenomenon under electron beam radiation was also reported in the literature. ${ }^{5}$

The melting process of the nanoparticles was recorded on video, which was then analyzed frameby-frame. A sequence of TEM images showing the melting and coalescence of solder nanoparticles before and after purification process are shown in Figs. 6 and 7, respectively. Already a short exposure time caused a corresponding local temperature rise, and the starting inter-diffusion of the atoms caused the growth and coarsening of the particles. As seen in the sequential frames in Fig. 6, in the first $40 \mathrm{~s}$ of exposure, the particles became more compact, supposedly bonded to each other through sintering. As stated before and as shown in Fig. 8, as-synthesized nanoparticles comprised an inner core of crystalline SAC alloy (mostly $\beta$-Sn), surrounded by an amorphous shell of $\mathrm{SnO}_{x}$. Since the melting point of this oxide shell is higher than the metallic core, the liquid phase appeared at first only in the innermost part of the particle. As the local temperature rose further, the liquid drop quickly expanded in size, and liquid spurted through the oxide shell after the solid core disappeared. The tin oxide shell enclosing the particle is compelled to expand to accommodate the larger liquid volume of the core. ${ }^{22}$ 

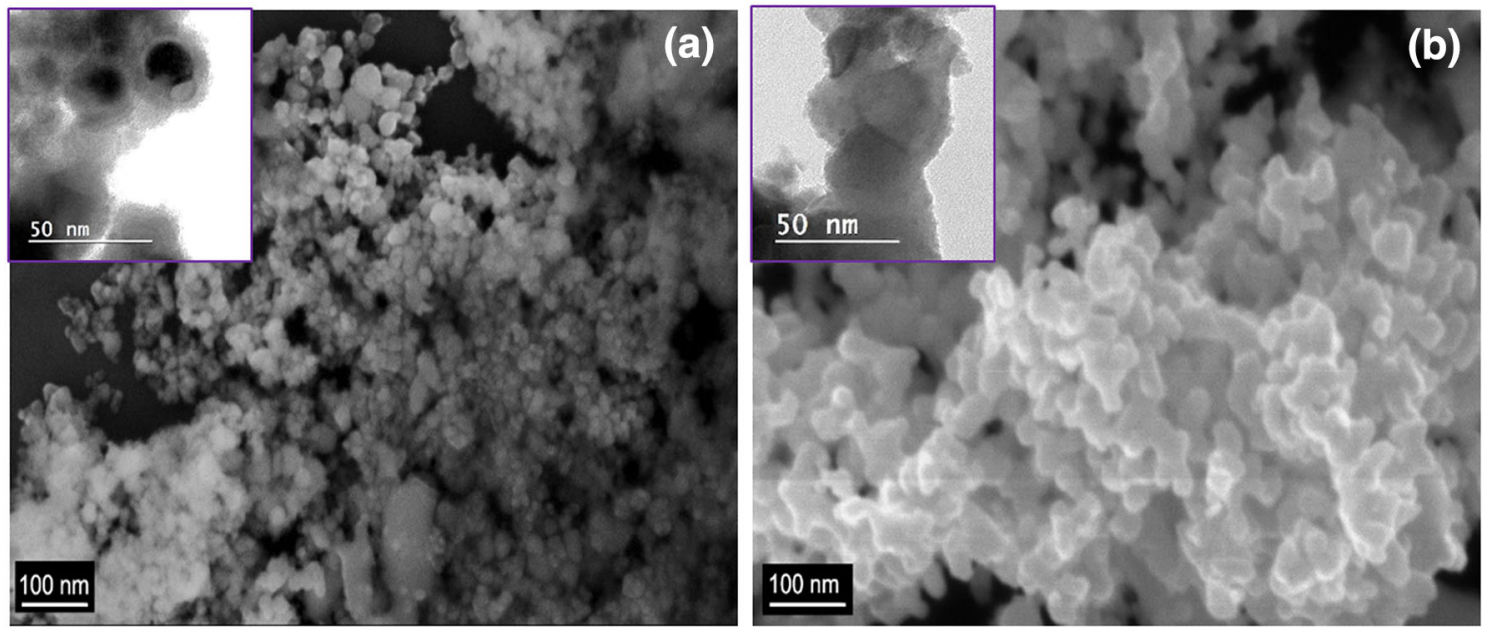

Fig. 4. Nanoparticles morphology: as-synthesized nanoparticles (a) and processed nanoparticles after purification (b).
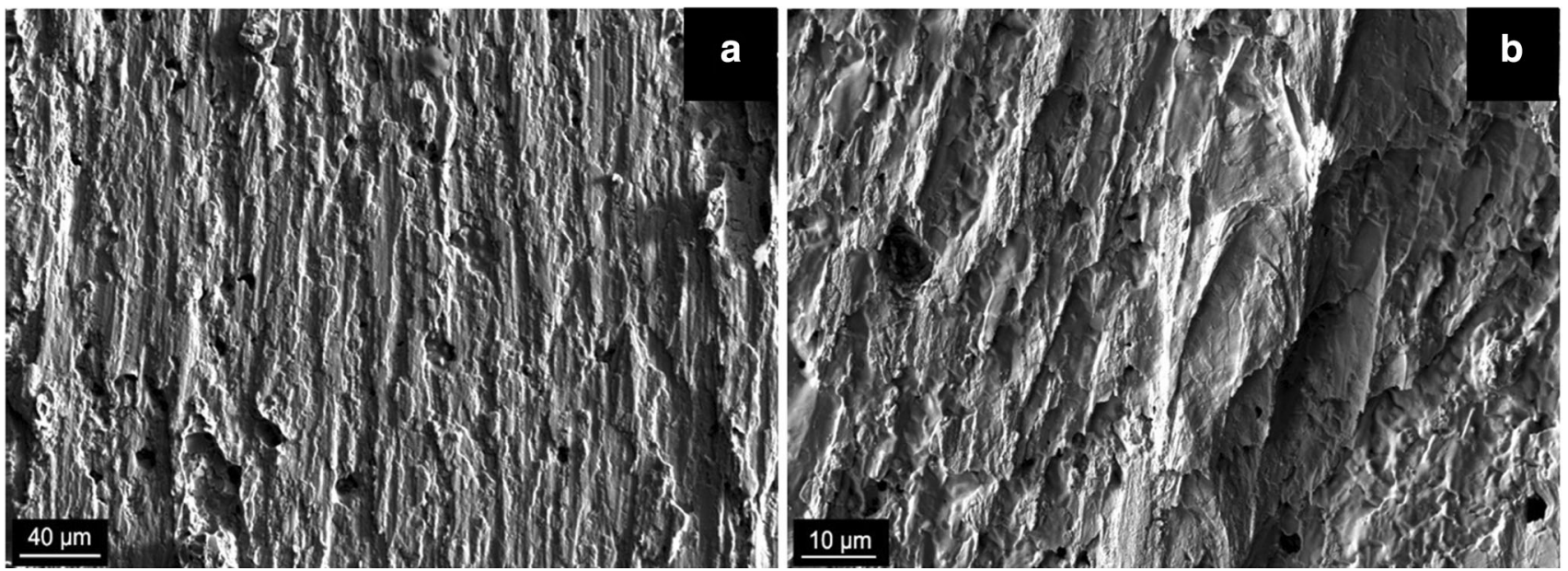

Fig. 5. SEM fractograph of the solder nano-joint after purification processing (P-S1), indicating a ductile fracture mode with the typical shear bands in two magnifications $(a, b)$.

The volume-change associated with melting of Sn-based alloys can be estimated by $\Delta V_{\text {melt }} / V_{0}$ where the density of $\mathrm{Sn}$ in the solid and liquid states are $7.310 \mathrm{~g} \mathrm{~cm}^{-3}$ and $6.973 \mathrm{~g} \mathrm{~cm}^{-3}$, respectively ${ }^{23}$ and $V_{0}$ is the initial volume. Therefore, the calculated volume change can be estimated to be $+4.8 \%$. Considering the volume of a single particle $\left(V=(4 / 3) \pi r^{3}\right)$, the volume change can be formulated as:

$$
\frac{\mathrm{d} V}{\mathrm{~d} r}=4 \pi r^{2}=\frac{3 V}{r}
$$

Rewriting Eq. 5 easily finds that the radial strain $(\mathrm{d} r / r)$ is one third of the volume change upon melting $(+1.6 \%)$, which, in turn, is the tangential strain in the oxide shell. To contain the larger liquid volume, the oxide shell must undergo an approximately $1.7 \%$ strain under plane-strain conditions. Thus, a tangential stress develops in the oxide shell at this stage. The oxide cracks when this stress exceeds a critical level, letting the pressurized liquid inside spurt through the failed region.

By comparison between Figs. 6 and 7, it can be inferred that after $93 \mathrm{~s}$, an almost perfect liquid sphere has been formed for the processed nanoparticles (Fig. 7), whereas for the as-synthesized nanoparticles even after $107 \mathrm{~s}$, the melting process has still not been accomplished, while some nanometric encapsulated liquid droplets have been formed (Fig. 6). This phenomenon can be attributed to the much thicker oxide shell of as-synthesized particles, which managed to withstand the volume change associated with melting.

Employing a thin-walled pressure vessel mechanics for the oxide shell as given in Eq. 6, indicates that the maximum pressure on the stressed oxideshell $\left(P_{\mathrm{S}}\right)$ due to the internal pressure of the liquid SAC alloy $\left(P_{\mathrm{L}}\right)$ has an inverse relation to the thickness of the oxide shell $(t){ }^{24}$ 


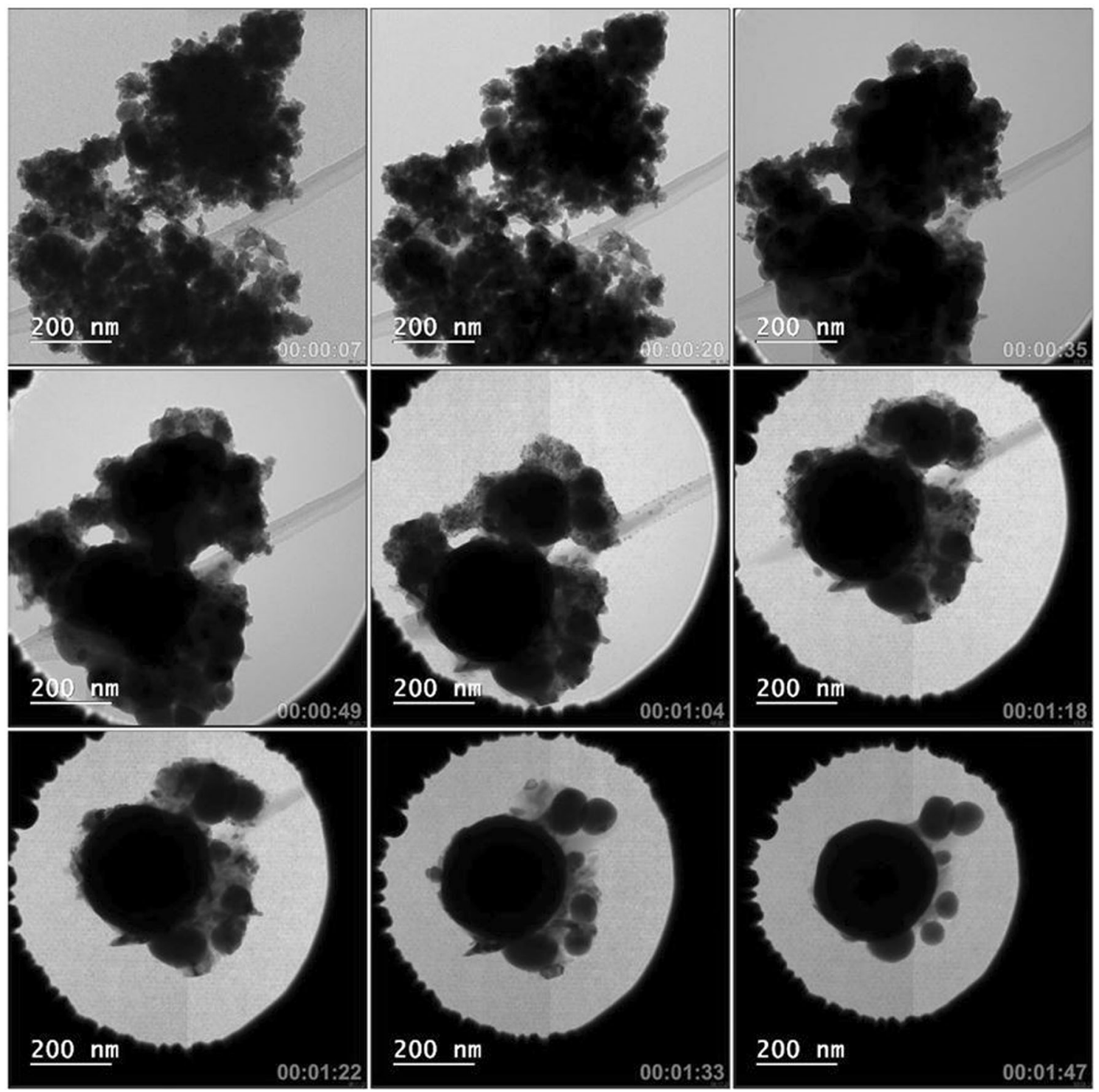

Fig. 6. TEM images showing melting and coalescence sequences of as-synthesized nanoparticles.

$$
P_{\mathrm{S}}=P_{\mathrm{L}}(r / 2 t)
$$

As inferred from this formula, the lower the thickness of the oxide shell, the higher the stress induced through the shell and the higher the probability that this layer ruptures upon melting. That can clearly justify the key role of the purification process, which diminished the oxide shell of the particles and facilitated the melting transformation of the particles.

Moreover, considering Eq. 6, the smaller the particle size, the lower the pressure in the oxide film; therefore, the harder it gets to break the oxide shell. This is also consistent with the TEM observations which pinpoint that although smaller nanoparticles essentially should melt prior to bigger ones due to the size-dependent depression of the melting temperature, their coalescence might on the other hand become retarded or even completely prevented as a consequence of the oxide shell.

In Fig. 9a and $\mathrm{b}$ the final configuration of the molten nanoparticles in the TEM, both as-synthesized and after purification, is compared. Analogous to the liquid features in the TEM studies, the features of the solidified solder after DSC heat treatment up to $350^{\circ} \mathrm{C}$ also revealed a neat spherical solder ball for the processed particles, whereas for the as-synthesized ones several smaller solder balls as well as a noticeable contribution of impurities were observed (Fig. 9c and d).

\section{Particle Size Transition upon Processing}

In Fig. 10a the DSC curves of the as-synthesized (a) and the processed nanoparticles (b) are presented. One can clearly discern two thermal effects in curve (a): heat absorption accompanied by an 


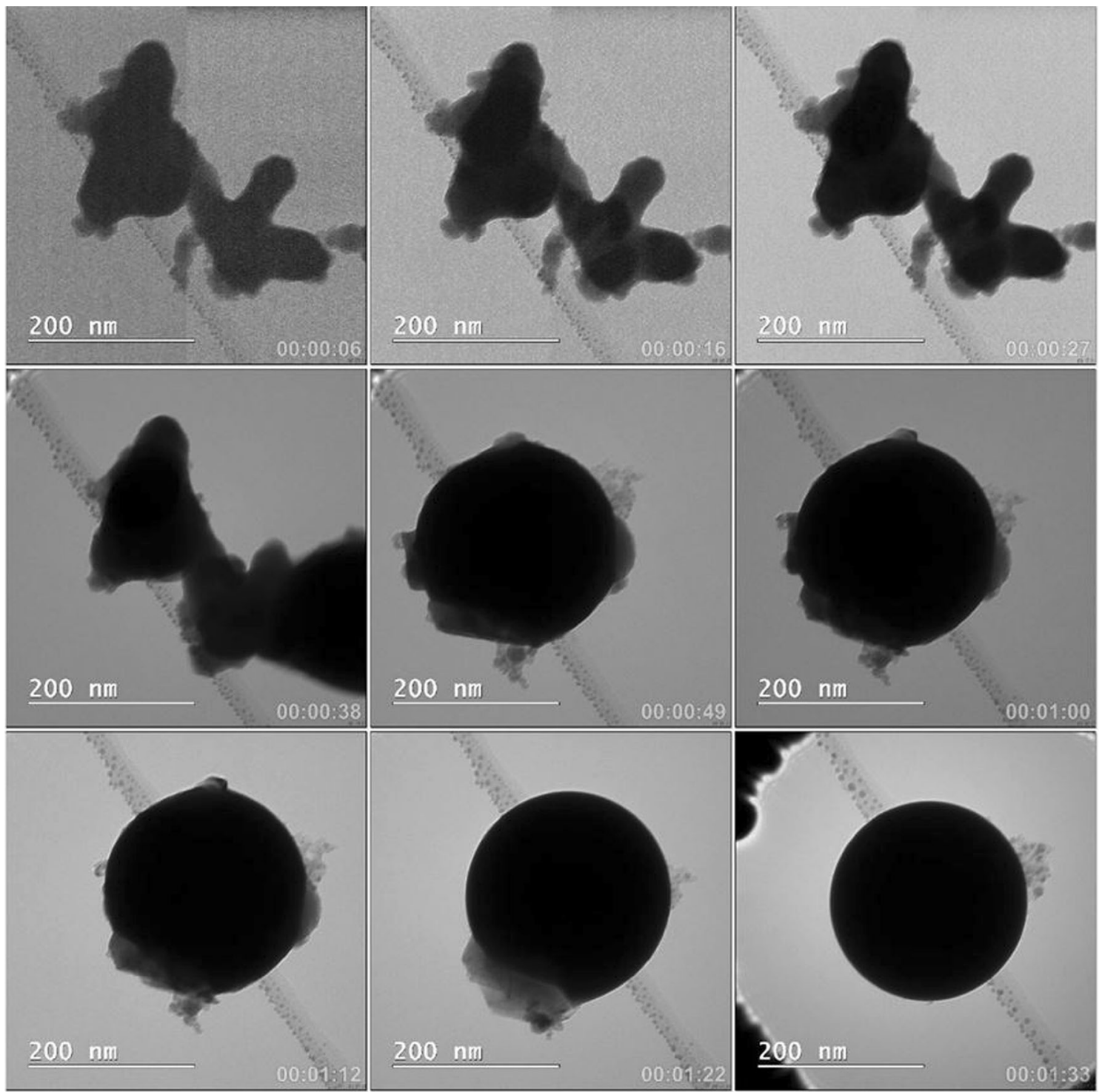

Fig. 7. TEM images showing melting and coalescence sequences of the processed nanoparticles after purification.

endothermic peak in accordance to the melting transformation and heat emission accompanied by an exothermic peak. Curve (b) also shows the endothermic melting peak, though at higher temperature, but the exothermic effect has virtually disappeared. This exothermic peak is probably an indicator of the rearrangement of the tin atoms in the amorphous shell of the nanoparticles or, generally speaking, this peak corresponds to the crystallization of the tin oxide shell as discussed in detail by Roshanghias et al. ${ }^{7}$ The disappearance of this exothermic peak in curve (b) is likely to be an evidence for the removal of the oxide shell through the purification process. Another explanation might be that the exothermic peak corresponds to rapid oxidation of the erupted liquid Sn from the oxide shells, but this cannot be distinguished from the $\mathrm{Sn}$ oxide crystallization reaction.
As observed, the melting transition took obviously place over a temperature range of about $30^{\circ} \mathrm{C}$, which is attributed to the size distribution of the nanoparticles. ${ }^{7,25,26}$ On the other hand, for the nanoparticles after the purification procedure, this temperature range became considerably narrower and the onset was shifted to higher temperature, pointing to an increase in the average size of the particles through the process. It can be speculated that as the tin oxide layer encapsulating and passivating the metallic layer dissolved in the solution, surfaceactive nanoparticles regained their activity; this might have enabled a direct contact with neighboring particles leading to coalescence as a major growth pathway, known as Ostwald ripening. ${ }^{27}$ The evolution in terms of particle size and morphology in accordance to this speculation is evident in Fig. 4b in comparison to Fig. 4a. As deduced from 
these two figures, a number of spherical nanoparticles after processing merged into "Tetris-like" features.

As inferred from Table I, the increase in the melting temperature after the purification process is much more significant for smaller particle sizes, whereas for samples $\mathrm{S} 1$ and $\mathrm{S} 2(18 \mathrm{~nm})$ an increase of the onset temperature of $15^{\circ} \mathrm{C}$ was observed after

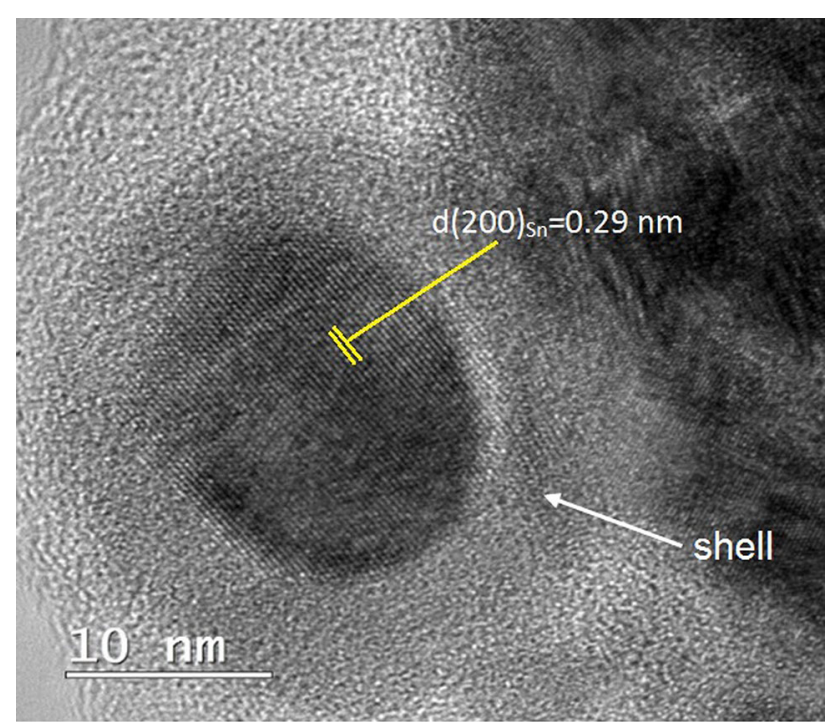

Fig. 8. Core-shell structure of the as-synthesized nanoparticles. purification, samples S3 $(34 \mathrm{~nm})$ and $\mathrm{S} 5(50 \mathrm{~nm})$ showed an increase of only 7 or $3^{\circ} \mathrm{C}$, respectively.

Considering the kinetics of the growth process and its dependence on particle size, it was determined to reduce the time of exposure to the solution to less than 2 min and to employ the buffer solution rather than an aqueous $\mathrm{HCl}$ solution, where the acidity of the solution is better controllable. Initial

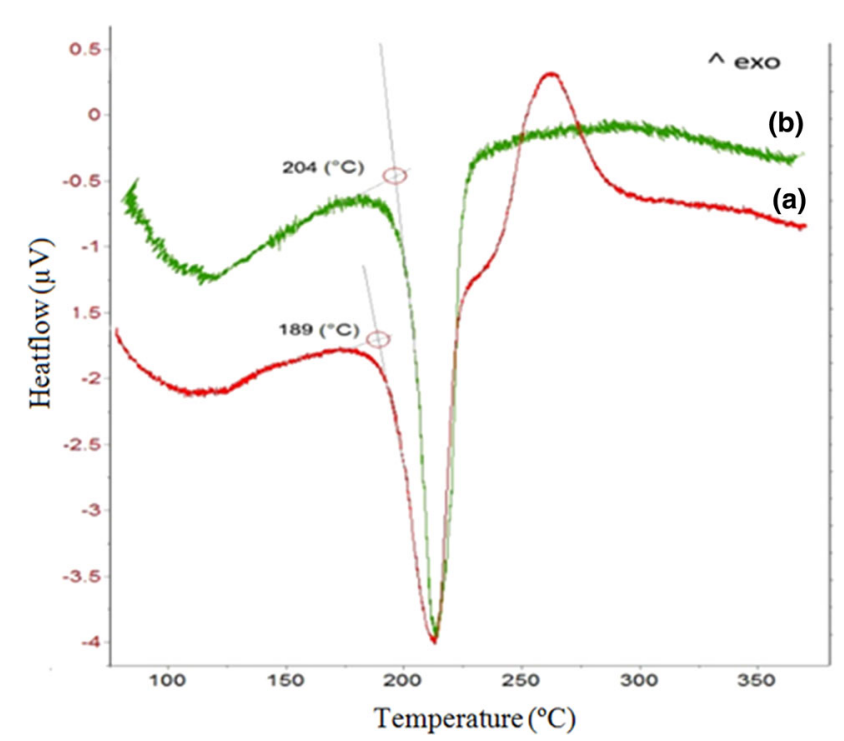

Fig. 10. DSC curves of the as-synthesized (a) and processed (b) nanoparticles
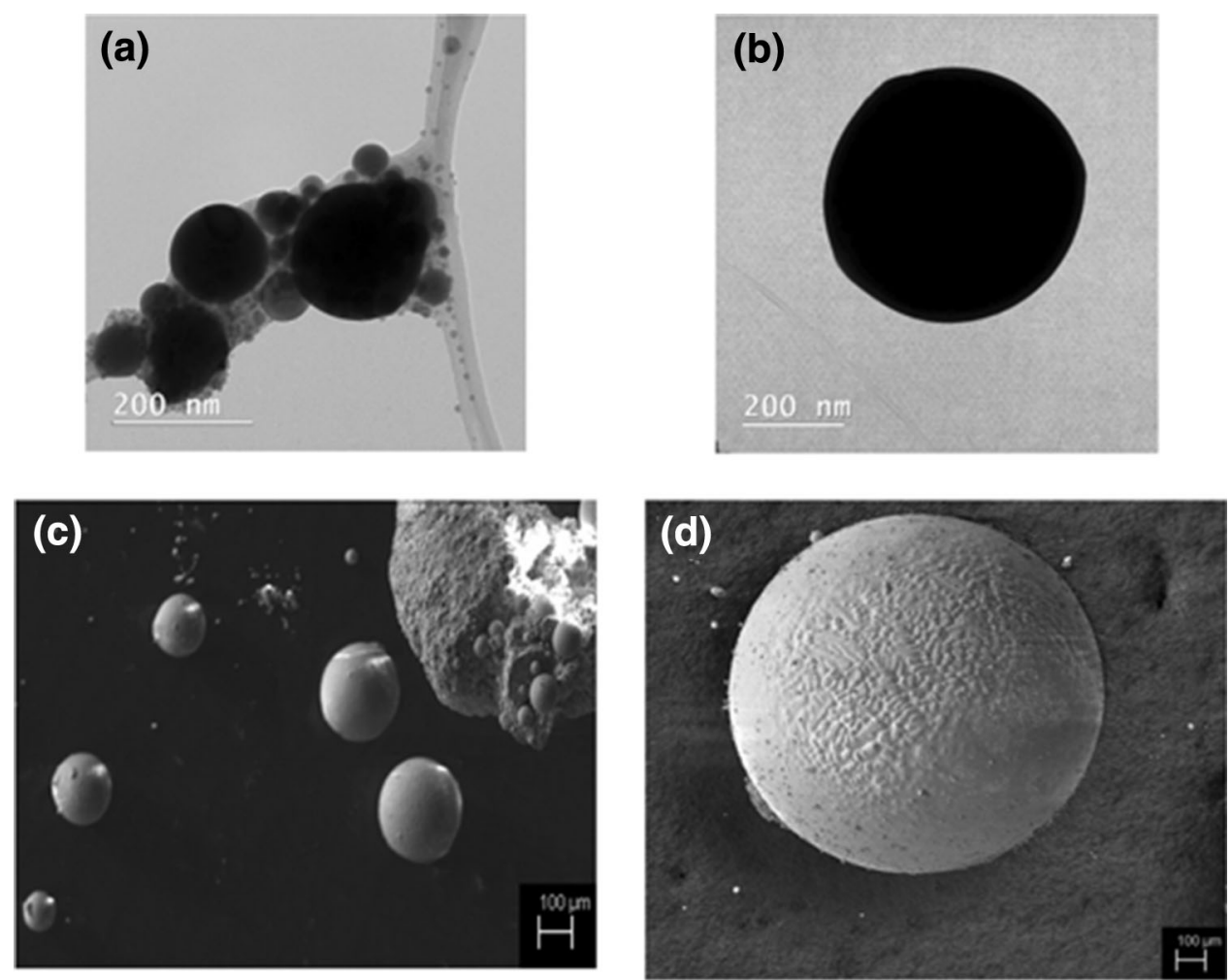

Fig. 9. The final structure of the as synthesized $(a, c)$ and processed (b, d) nanoparticles, (a) and (b) show the liquid state of particles in TEM chamber, (c) and (d) show the SEM images of the solidified samples after DSC heat treatment. 
studies, which were performed in aqueous and aggressive acidic solutions $(\mathrm{pH} \approx 1)$, resulted in an explosive growth of the particle sizes, as the surfaceactive nanoparticles tend to merge rapidly.

In fact, although increasing the acidity and/or the exposure time to the acidic solution clearly enhances the mechanical characteristics of the nanojoints, coarsening and coalescence of the nanoparticles might occur, ultimately deteriorating the microstructure and degrading the properties that are enhanced at the nanoscale, i.e. size melting point depression. Consequently, it was found that very careful attention must be paid when a proper purification solution for the dissolution of the oxide shell is designed.

\section{CONCLUSION}

In this study, first-hand results are presented on the production feasibility of a prototype nano-solder paste as well as on the reliability of the corresponding solder joints. The results favor the conclusion that nanoparticle solders in their as-synthesized form cannot be readily implemented in the soldering process. It was found that the oxide shell surrounding the particle impede the coalescence of the molten core of the particles in the course of reflow process. This behavior was ascribed to the thickness of the shell, which apparently could resist the tangential strain due to the volume expansion associated with melting. The proposed purification technique, based on soaking the nanoparticles in an acidic buffer solution under stirring with a zinc rod, results in a clear improvement in the performance of the corresponding solder paste, e.g. in a considerable increase in the shear strength of the joint. This acidic treatment prior to soldering represents a viable technique to dissolve the oxide shell of the nanoparticles, while the exposure time and acidity level of the solution could also alter the particles size and their morphology.

\section{ACKNOWLEDGEMENTS}

Open access funding provided by University of Vienna. Financial support for this study came from the Austrian Science Fund (FWF) under Project Nos. P26304 and P27049. The authors want to acknowledge Dr. K. W. Richter for valuable suggestions and discussions and the support of Dr. St. Puchegger with the SEM studies. TEM investigations were carried out using the facilities at the University Service Center for Transmission Electron Microscopy at the Vienna University of Technology.

\section{OPEN ACCESS}

This article is distributed under the terms of the Creative Commons Attribution 4.0 International License (http://creativecommons.org/licenses/by/4.0/), which permits unrestricted use, distribution, and reproduction in any medium, provided you give appropriate credit to the original author(s) and the source, provide a link to the Creative Commons license, and indicate if changes were made.

\section{REFERENCES}

1. H. Jiang, K. Moon, and C.P. Wong, Microelectron. Reliab. 53, 1968 (2013).

2. J. Sopousek, J. Vrestal, A. Zemanova, and J. Bursik, J. Min. Metall. Sect. B: Metall. 48, 419 (2012).

3. K.J. Puttlitz and K.A. Stalter, Handbook of Lead-Free Solder Technology for Microelectronic Assemblies (Marcel Dekker Inc., New York, 2004), p. 239.

4. J.P. Koppes, K.A. Grossklaus, A.R. Muza, R.R. Revur, S. Sengupta, A. Rae, E.A. Stach, and C.A. Handwerker, Mater. Sci. Eng. B 177, 197 (2012).

5. Y. Shu, K. Rajathurai, F. Gao, Q. Cui, and Z. Gu, J. Alloys Compd. 626, 391 (2015).

6. F. Frongia, M. Pilloni, and A. Scano, J. Alloys Compd. 623, 7 (2015).

7. A. Roshanghias, A. Yakymovych, J. Bernardi, and H. Ipser, Nanoscale 7, 5843 (2015).

8. Y. Gao, C. Zou, B. Yang, Q. Zhai, J. Liu, E. Zhuravlev, and C. Schick, J. Alloys Compd. 484, 777 (2009).

9. A. Roshanghias, J. Vrestal, A. Yakymovych, K.W. Richter, and H. Ipser, CALPHAD 49, 101 (2015).

10. K.C. Yung, C.M.T. Law, C.P. Lee, B. Cheung, and T.M. Yue, J. Electron. Mater. 41, 313 (2012).

11. Solder Paste Task Group, Requirements for Soldering Pastes “J-STD-005" (Electronic Industries Alliance and IPC, Arlington, VA, 1995).

12. J.S. Hwang, Solder Paste in Electronics Packaging, (Springer, New York, 2012), p. 52.

13. Association Connecting Electronics Industries (IPC), Acceptability of Electronic Assemblies "IPC-A-610" (Bannockburn, IL, 2010).

14. H.M. Henao, C. Masuda, and K. Nogita, Int. J. Miner. Process. 137, 98 (2015).

15. F. Gao, K. Rajathurai, Q. Cui, G. Zhou, I. NkengforAcha, and Z. Gu, Appl. Surf. Sci. 258, 7507 (2012).

16. B.S. Kim, J.C. Lee, H.S. Yoon, and S. Kim, Mater. Trans. 52,1814 (2011).

17. S. Itoh and K. Maruyama, High Temp. Mater. Process 30, 317 (2011).

18. M. Pecht, Soldering Processes and Equipment (Wiley, New York, 1993), p. 9.

19. V. Simic and Z. Marinkovic, J. Less Common Met. 95, 259 (1983).

20. A. Roshanghias, A.H. Kokabi, Y. Miyashita, Y. Mutoh, and H.R. Madaah-Hosseini, J. Mater. Sci. 24, 839 (2013).

21. P. Zimprich, A. Betzwar-Kotas, G. Khatibi, B. Weiss, and H. Ipser, J. Mater. Sci. 19, 383 (2008).

22. G.A. Storaska and J.M. Howe, Mater. Sci. Eng., A 368, 183 (2004).

23. J. Emsley, The Elements (Clarendon Press, Oxford, 1989), p. 196.

24. R.W. Hertzberg, Deformation and Fracture Mechanics of Engineering Materials, 4th ed. (Wiley, New York, 1996), p. 11, 22, 45, 233.

25. R. Garrigos, P. Cheyssac, and R. Kofman, Z. Phys. D 12 , 497 (1989).

26. W. Hu, S. Xiao, J. Yang, and Z. Zhang, Eur. Phys. J. B 45, 547 (2005).

27. A. Pomogailo and G.I. Dzhardimalieva, Nanostructured Materials Preparation via Condensation Ways (Springer, Dordrecht, 2014), p. 13. 